\title{
A new approach for impedance matching rotman lens using defected ground structure
}

\author{
Mohammed K. Al-Obaidi ${ }^{1}$, Ezri Mohd ${ }^{2}$, Noorsaliza Abdullah ${ }^{3}$, Samsul Haimi Dahlan ${ }^{4}$ \\ ${ }^{1,2,3,4}$ Department of Communication Engineering, Faculty of Electrical and Electronic Engineering, \\ Universiti Tun Hussein Onn Malaysia (UTHM), Johor, Malaysia \\ ${ }^{1}$ Department of Network Engineering, Faculty of Engineering, Al-Iraqia University, Baghdad, Iraq
}

\section{Article Info}

Article history:

Received Oct 21, 2019

Revised Dec 30, 2019

Accepted Jan 31, 2020

\section{Keywords:}

Beamforming

Defected ground structure

Impedance matching

Rotman lens

Steerable antenna

\begin{abstract}
Many recent radar applications and smart antenna are based on the electronically steerable beam in order to increase the performance of targeting the desired scan angle with the high performance of gain and directivity. Scanning angle with $\pm 26^{\circ}$ based on Microstrip Rotman lens and design frequency $2.45 \mathrm{GHz}$ is presented in this study. Five beam ports provide five output beams directed the beams in five different scanning angles in the azimuth plane is provided. The traditional matching method by tapering the transmission line in order to guarantee a smooth energy transition from the $50 \Omega$ input ports is replaced by Defected Ground Structure to achieve an acceptable return loss with a linear progressive phase for each beam port. The new approach is providing increasing in the scan angle. Besides, the size miniaturization is achieved by removing the tapering length and reduces the total size of the lens length by $23.67 \mathrm{~mm}$. The proposed model is implemented using Computer Simulation Technology (CST) using the FR-4 substrate and the measurements lead to a good validation.
\end{abstract}

This is an open access article under the CC BY-SA license.

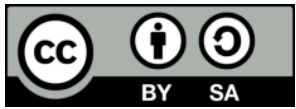

\section{Corresponding Author:}

Mohammed K. Al-Obaidi,

Department of Communication Engineering,

Universiti Tun Hussein Onn Malaysia (UTHM),

86400 Parit Raja, Batu Pahat, Johor, Malaysia.

Email: ge170108@siswa.uthm.edu.my

\section{INTRODUCTION}

Compactness and power loss are considered the main factors design in the modern wireless communications system. Besides, the smartness is considered the key technology of the recent wireless communication system while the beamforming technique is a cornerstone of the antenna to be smarter to direct the beam towards the desired angles in order to work in a high-quality environment and increase the data capacity limit [1-5]. The need for a fasting scanning area by forming an electromagnetic beam is encouraged many researchers to invent radar system based on the electric steerable to eliminate the use of the mechanical movement of the array antenna such as Butler matrix and Blass matrix are the most earlier microwave circuit considered as beamforming network BFNs. However, the design complexity and the shifting beam based on the frequency changing is the most disadvantaged of these techniques [6].

W. Rotman introduced a technique based on the optical theory in order to provide a progressive linear phase shift from the input port to feed the array antenna to form the beam in the required angle by using lens [7]. Rotman lens is a beamforming network based on the path length difference to introduce a phase shift for each input beam. Besides, this property of the lens to provide the linear phase shift introduce 
it as a true time delay microwave circuit because the beam shifting is required only a single frequency. Furthermore, easy to fabricate in microstrip model, compactness, less complexity compared with other BFNs are the main properties of the Rotman lens. Numerous civilian and military sensing applications depend on the Rotman lens to direct the radiation beam scan angle such as sensing of the automotive platform [8], radar system [9] and satellite communication [10].

This study will be divided into two main sections. The first section will be introducing the design implementation of the Rotman lens to provide $\pm 26^{\circ}$ scanning angle with center frequency $2.45 \mathrm{GHz}$ Industrial, Scientific, and Medical (ISM) radio band. While the second section will cover the techniques are used for matching the impedance between the input beam ports and the lens cavity. Furthermore, the impedance matching using defected ground structure (DGS) and its effect on the lens performance will be implemented and explained. Finally, the comparison between two approaches in terms of return loss, and size reduction will be introduced. Generally, Rotman lens is a multi-ports microwave circuit constructed from the optical theory, the construction of the design is based on the determination of the locations for the beam ports, receive ports and the array antenna elements beside the length of the transmission lines which are connected between receive ports and antenna array as explained in Figure 1.

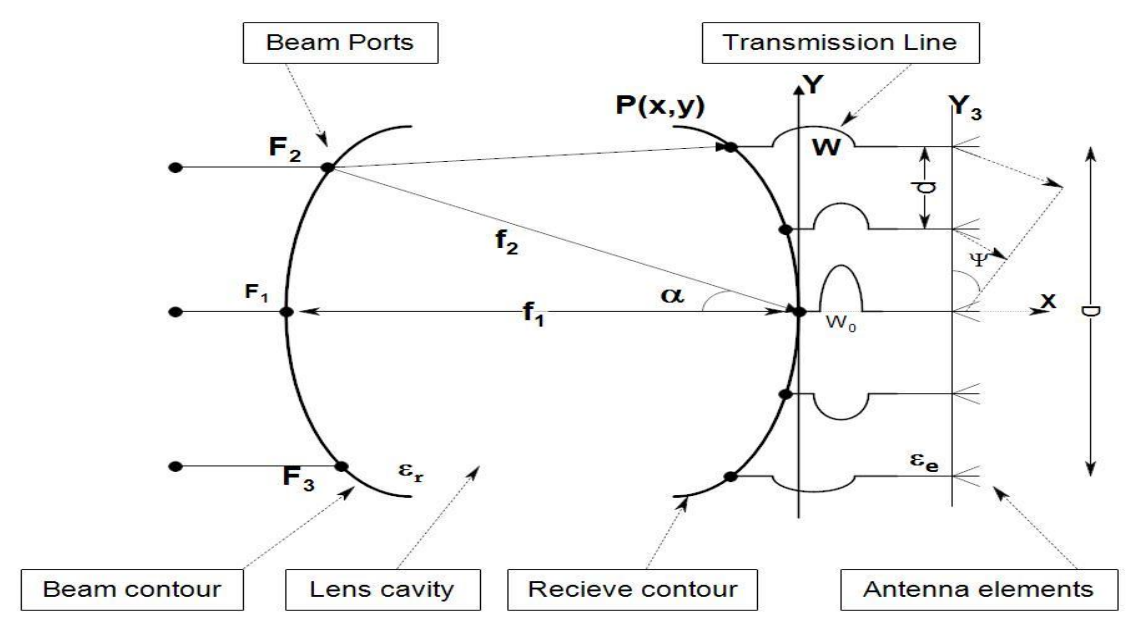

Figure 1. Rotman lens geometry [7]

Beam ports are input ports for the lens cavity in which the excitation frequency will be applied and directed to the lens cavity. Then, the lens cavity will forward the exciting energy to word the receive ports. On the other side, the antenna array will be fed through the transmission lines. While the sides-walls of the lens will be terminated by the dummy ports connected with matched $50 \Omega$ loads in order to absorb the incident reflections and save the phase performance inside the lens cavity.

\section{ROTMAN LENS DESIGN PROCEDURES}

The concept of the beamforming techniques is based on providing a linear phase shifting to feed the array of the antenna. The value of the phase shift linearity is related to the scan angle of the out beam [6]. Rotman lens is a microwave multi ports structure. Its formulation provides a path length delay for input port different from the other beam ports based on the location of the input beam ports, receive ports and the length of the transmission line. Three beam focal points are located in the beam contour $\left(F_{1}, F_{2}\right.$, and $\left.F_{3}\right)$ provides theoretically zero phase error with the subtended angle $\alpha$. In practical, more than three focal points are needed to provide a multi-switching beam at different angles, these non-focal points generate a phase error, besides the beam contour, can be circular or elliptically shape [11]. The receive points are located on the receiving contour at $(\mathrm{X}, \mathrm{Y})$ coordinate. While the antenna elements fed using these receive points by the connected transmission lines with length $\mathrm{W}$. It can be noticed that the length of the transmission line saves the phase-shifting provided to the array elements. The antennas arrays are placed at the lens aperture at locations $\mathrm{Y}_{3}$ with adjacent distance $\mathrm{d}$, which has the main control contribution of the sidelobe level for the radiation pattern [11].

The lens design materials permittivity can be modeled using the homogenous material in the for the lens cavity $\varepsilon_{r}$ and transmission lines $\varepsilon_{e}$ or inhomogeneous materials in order to enhance 
the performance of the lens such as low loss graded materials [12]. On the other hand, ports with $50 \Omega$ loads will be terminated the sides of the lens cavity in order to absorb the incident energy and reduce the inside reflections which decrease the phase quality reached to the radiator elements. The formulation design equations of the lens can be derived according to the optical theory by equalizing the path from the focal points to the lens aperture as reported in [13]. Where the focal length $f_{1}$ has a direct impact on lens dimensions generally and especially to the operation bandwidth as compared these results to the work reported in [14]. Furthermore, the full structure of the microstrip lens model will include the tapering line in order to achieve an impedance matching between the lens cavity and the $50 \Omega$ transmission line impedance. While in this study Defected Ground Structure (DGS) will be used to achieve the impedance matching as it will be explained in the final sections of this work.

\section{IMPLEMENTATION ANALYSIS AND RESULTS}

This section will be classified into two subsections. In the first section, the lens geometry will be determined besides the final prototypes of the lens including the tapering line will be introduced. While, the second section, the impedance matching between $50 \Omega$ beam ports and lens cavity will be explained. On the other hand, the suggested approach for the impedance matching using defected ground structure will be implemented and discussed. The simulation will be carried out using CST Microwave Studio.

\subsection{Lens implementation using tapering line}

A microstrip lens will be implemented in this section. Besides, design specifications are proposed as Table 1 explained. The beam contour and the receive contour besides the coordinate for the locations of the ports are determined by solving the design of the equations for the given variables as Figure 2(a) explained. Then, the full lens geometry including the tapering line, dummy ports at the sides-walls and transmissions lines are explained in Figure 2(b). While the full ground plane is used in this design. The tapering line for impedance matching between transmission lines and the lens cavity is based on the gradual transition impedance between the high impedance transmission lines with $50 \Omega$ and the unknown low impedance for the lens cavity. The challenge in the matching determination is to find a suitable taper length by an optimization process. However, the optimization is used because of the difficulty to determine the exact impedance for the lens cavity due to its non-uniform shape. While, in the uniform transmission line, the impedance can be determined in order to find the exact taper length for matching $[15,16]$.

Table 1. Lens design parameters

\begin{tabular}{cccccc}
\hline Design variable & value & Design variable & value & Design variable & value \\
\hline No. of beam ports & 5 & scan angle $\alpha$ & $\pm 26^{\circ}$ & focal length $\mathrm{f}_{1}$ & $1.45 \lambda_{\mathrm{g}}$ \\
No. of antenna ports & 4 & relative permittivity $\varepsilon_{\mathrm{r}}$ & 4 & displacement distance $\mathrm{d}$ & $0.43 \lambda_{\mathrm{o}}$ \\
No. of dummy ports & 8 & loss tangent & 0.025 & substrate thickness & $1.565 \mathrm{~mm}$ \\
center frequency & $2.45 \mathrm{GHz}$ & copper thickness & $0.035 \mathrm{~mm}$ & width *length & $197.21 * 211.08 \mathrm{~mm}$ \\
\hline
\end{tabular}

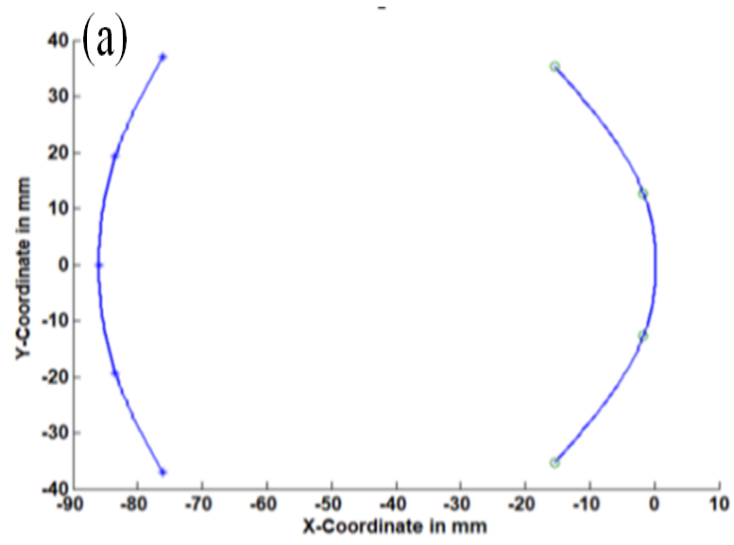

(a)

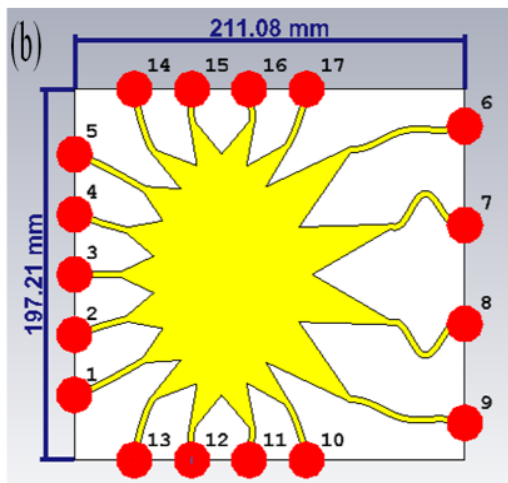

(b)

Figure 2. Lens configuration, (a) Lens contours, (b) Lens geometry CST model 
In the lens geometry, it obvious that each beam port has different taper length in order to yield an acceptable return loss according to its location on other terms impedance value, for example, port one length is $16.98 \mathrm{~mm}$ and the length of port two and three $17.49 \mathrm{~mm}$, and $17.54 \mathrm{~mm}$ respectively. While the input impedance for the taper line is $50 \Omega$; on the other terms the calculated width for the transmission line with FR-4 substrate material permittivity and thickness $1.565 \mathrm{~mm}$ is $3.21 \mathrm{~mm}$. The return loss simulation results for the beam ports are carried out using CST Microwave Studio with explained frequency range as shown in Figure 3(a).

It can be concluded from the return loss results that the minimum bandwidth of the beam port is $990 \mathrm{MHz}$ with minimum return loss for the port two with $-39.24 \mathrm{~dB}$ while port three has the maximum return loss with $-19.7 \mathrm{~dB}$ at the design frequency $2.45 \mathrm{GHz}$. The surface current distribution for the port three excited by $2.45 \mathrm{GHz}$ and all the other ports are loaded with $50 \Omega$ load is shown in Figure 3(b). Hence, a circular phase performance distribution inside the lens cavity can be indicated without distortion from the excited port three. On the other hand, the dummy ports absorb the incident energy from sidewalls without reflections. Array elements will be connected to the lens in order to detect the radiation pattern performance and scan angle. The full geometry model for the lens and the antenna elements is shown in Figure 4(a).

While the simulated results for the radiation pattern when the excitation is applied for each beam ports separately with $2.45 \mathrm{GHz}$ are explained in Figure 4(b). The switching radiation pattern takes a place at the $26^{\circ}, 13^{\circ} 0^{\circ},-13^{\circ},-26^{\circ}$ angles according to the excitation ports (1-5) respectively. In the following section, the defected ground structure (DGS) will be proposed in order to match the impedance between the beam ports and the lens cavity. The effect of DGS on the phase performance and the radiation pattern besides the matching process will be discussed.
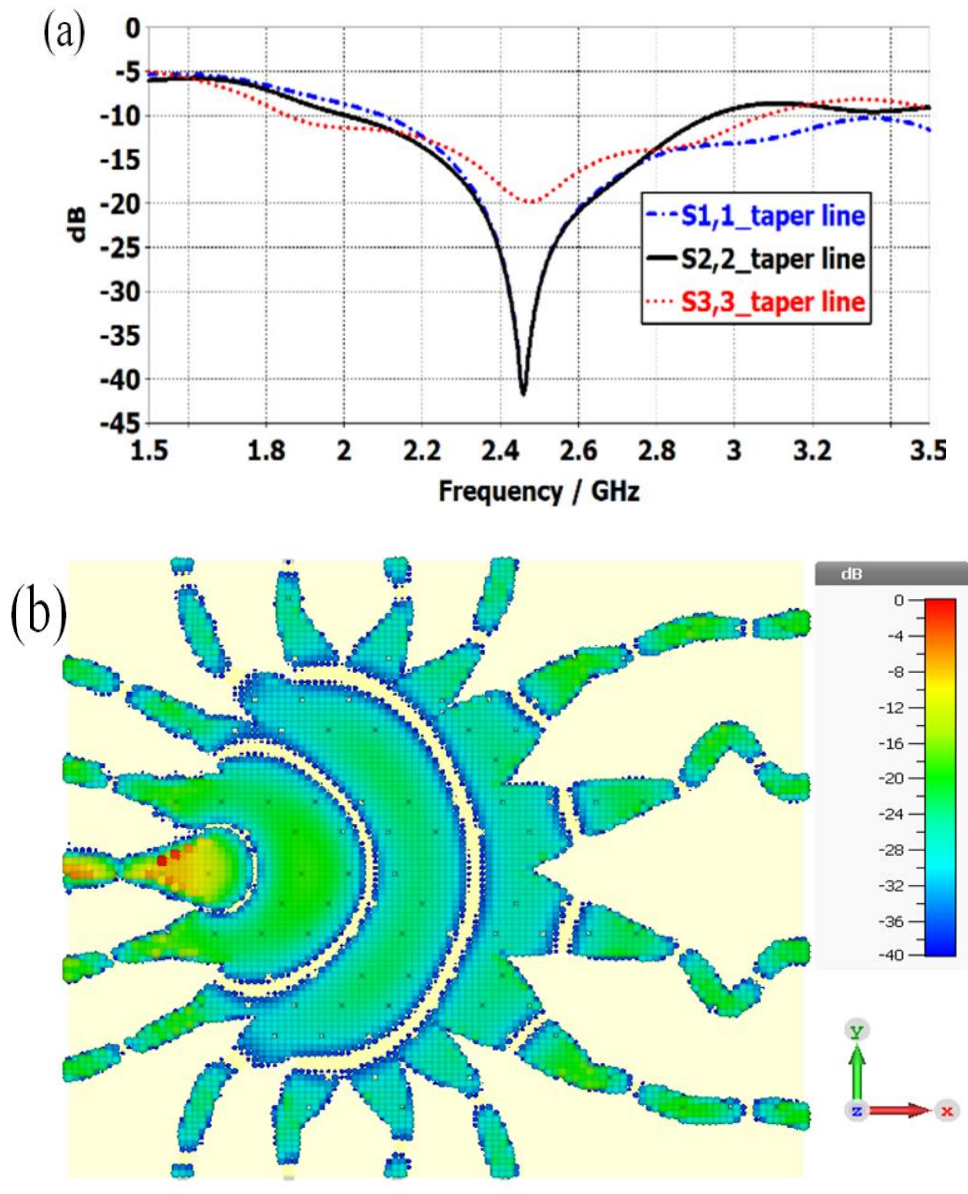

Figure 3. Lens performance, (a) Return loss for beam ports, (b) Surface current distribution 


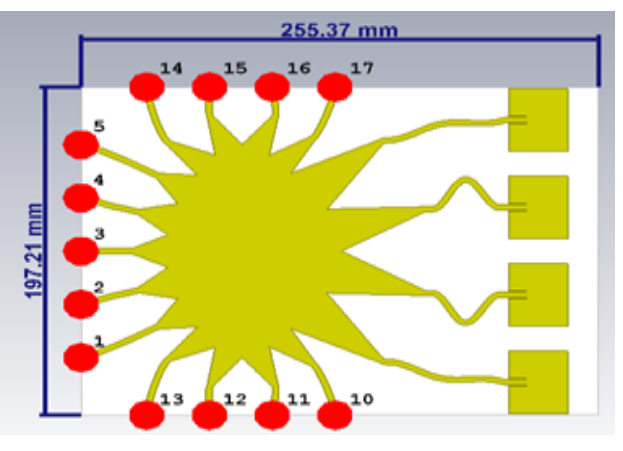

(a)

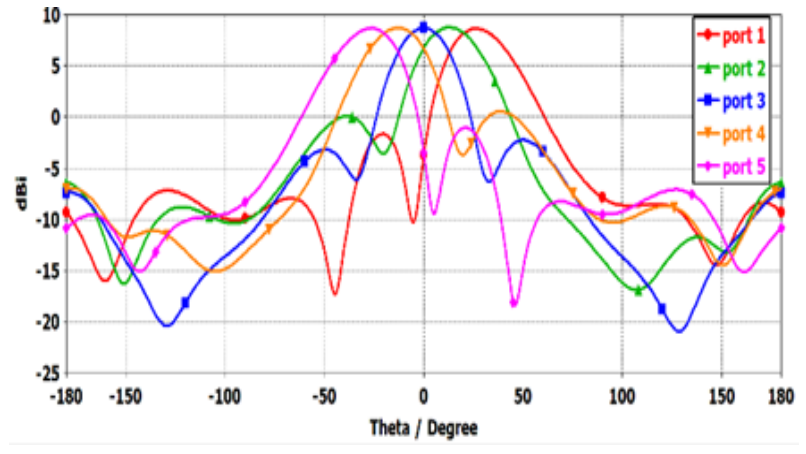

(b)

Figure 4. Beamforming system configurations, (a) Lens and array elements,

(b) Radiation pattern at $2.45 \mathrm{GHz}$

\subsection{Defected ground structure implementation with lens}

An embedded defected shape in the ground plane of the microstrip circuit has the ability to modify the inductance and capacitance values of the specified location [17]. The first 1-D first DGS was proposed by K-Chul-Soo in order to enhance the effective inductance to control the cut off frequency in 2000 [18]. Compactness, low profile, easy to fabricate and simplicity in design make much modern wireless communication applications use the technique of DGS. Bandwidth enhancement, impedance matching, mutual coupling between adjacent transmission lines, suppression harmonic, cross-polarization in microstrip antenna and control the band stop of microstrip filters are application areas of DGS for the wireless systems [19-24]. There are many microstrip antennas and microwave circuit use DGS for impedance matching. However, the difficulty to apply DGS to match the $50 \Omega$ beam ports line to the lens cavity can be summarized into three problems; the first side of the problem is the unknown impedance of the lens cavity that leads to difficulty for constructing the equivalent circuit. While the second problem is the adjacency of the ports which increases the difficulty because of the effect of applying DGS to a single port will modify characteristics for the neighbor ports. Finally, the third problem is occurred due to the ability of the DGS to change the value of the capacitance and inductance when it is applied under the microstrip line, it has a direct impact on the phase performance as a result of applying such as overlapping phase and distortion phase will change the linearity phase shift of the beam ports achieved by the lens design theory which is the main aim of lens to direct the output beam in the desired angle. However, there are many advantages to finding a suitable DGS to match beam ports with lens cavity, for example, provide the compactness and size reduction of the lens as a result of removing the taper transmission line length used for the traditional matching technique. In addition, the scanning angle of the beam will be increased as an outcome for DGS effectiveness to increase the phase shift to the coupling phase reached to receive ports as the next section will explain.

Accordingly, this section is aimed is to explain a method to balance impedance for the beam ports transmission line which has $50 \Omega$ and the low impedance for the lens cavity. Many DGS configurations are used in microwave circuit applications such as dumbbell shape [18] $\mathrm{H}$ shaped, spiral-shaped [25] and V shape [26]. Therefore, it can be concluded that most of the microwave circuits need a unique design depends on the desired applications and aim to be achieved by applying DGS. Consequently, DGS can be proposed under the lens cavity. As the first step of design, it can be determined that the impedance of the beam ports transmission lines is higher than the lens cavity because of the large area of the lens compared with the transmission lines. Therefore, it is required to increase the impedance of the lens cavity in order to match it with transmission lines impedance. Hence, the location of the DGS will be applied inside the lens cavity which will introduce a challenge to find the appropriate configuration to save the phase performance further balance the impedance. Dumbbell, $\mathrm{H}$ shaped and $\mathrm{U}$ shaped geometries are considered a superior impact in many microwave circuit [19]. However, it cannot use for the lens due to the phase distortion effect. Therefore, a new DGS configuration geometry was proposed in this study in order to achieve an acceptable matching result further saving phase performance as explained in Figure 5.

Depending on the surface current distribution and optimization results the proposed geometry can be applied underneath the lens geometry. The transmission line length L, width of the transmission line $\mathrm{H}$, curve width $\mathrm{R}$ and the circle diameter are the parameters to be considered for the proposed DGS geometry. 
Besides, the location of the DGS and the distance between the centers of the transmission line $\mathrm{L}$ has an impact to control the effect of the DGS to the phase and the impedance matching.

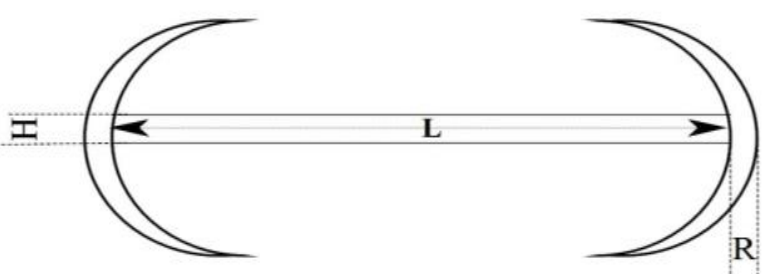

Figure 5. Proposed DGS model geometry

In the following, lens geometry after removing tapering transmission lines from the beam ports besides the defected are designed and applied on the ground plane are explained. It can be noticed that from Figure 6(a) that a section with a width equal to the beam port aperture and length $\mathrm{A}$ is applied to the lens geometry in order to achieve two goals. The first goal is to increase the isolation between adjacent beam ports and the second goal is to increase the ability of the non-excited ports to absorb the reflected energy wave and save phase performance. While the ground planes including defected configurations are shown in Figure 6(b). Thus, lens length decreased as a result of removing the tapering line by $23.67 \mathrm{~mm}$. Moreover, the defected model position related to the beam ports is explained in Figure 6(c) by hiding the substrate geometry.

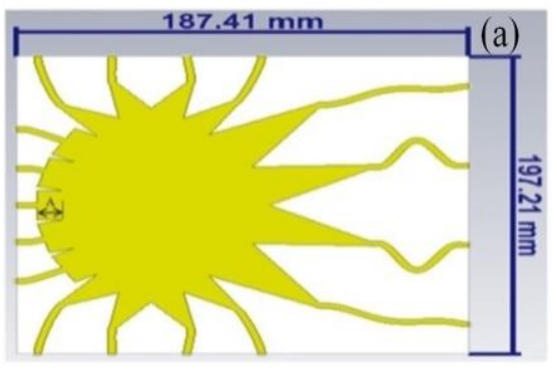

(a)

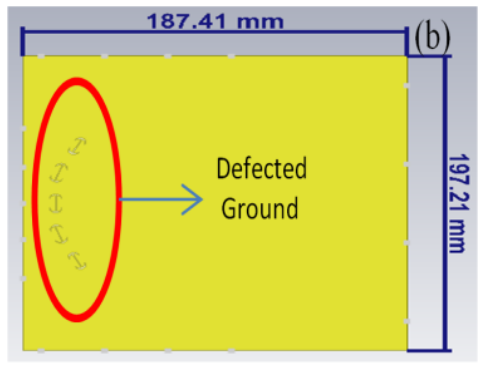

(b)

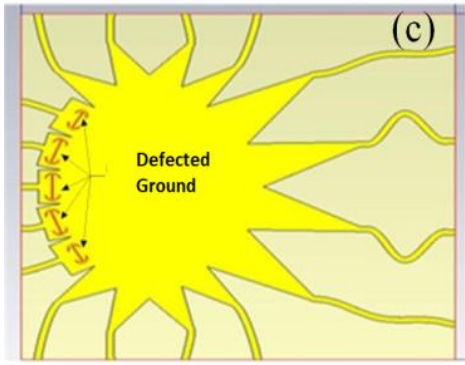

(c)

Figure 6. Lens with DGS, (a) Lens without beam ports tapering, (b) The defected ground plane,

(c) Defected ground front view

It is obvious that the large area of the lens cavity has low impedance compared with the $50 \Omega$ transmission line. Therefore, defected will be applied to the lens cavity in order to increase low impedance to match it with transmission line impedance. An optimization process is carried out in order to fit the defected dimensions and achieve acceptable return loss beside save phase performance. The fabrication process was carried out in order to test the performance of the proposed model as explained in Figure 7.

The proposed lens model front view is described in Figure 7(a) furthermore the defected model in the ground is explained in Figure 7(b). In order to measure the performance of the return loss, a vector network analyzer will be connected to the port input port of the lens. While the other ports of the lens will be connected to $50 \Omega$ loads in order to reduce the unwanted energy reflections and provided an impedance matching connection to the all received ports. On the other hand, return loss comparison between the full ground and defected ground simulation results for the beam ports are explained in Figure 8(a). While the return loss measurement compared with the CST Microwave Studio simulation is explained in Figure 8(b).

A Return loss measurement for the beam ports is carried out by manual switching the applied excitation with an explained range of frequency. Meanwhile, loads with $50 \Omega$ are connected to the other lens ports when each port is excited in order to reduce reflections that will occur from the non-excited ports. For the selected beam ports; port one, port two and port three the return loss measurements are explained a good validation compared with simulated calculated results using CST microwave studio. As a result of the applying defect on the ground plane, the total length of the model is decreased. Furthermore, return loss at $2.45 \mathrm{GHz}$ for port 3 is better than the taper line model with enhancement equal to $19.28 \mathrm{~dB}$. While the bandwidth is decreased for all ports for the defected ground model as explained in Table 2. 


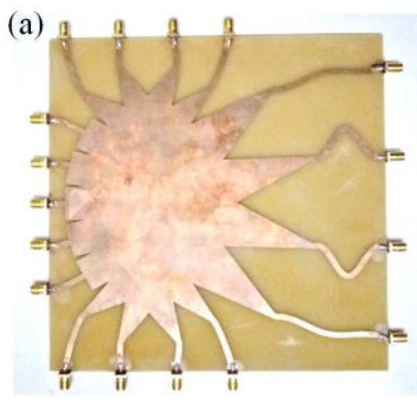

(a)

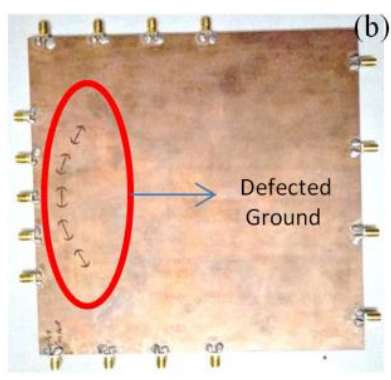

(b)

Figure 7. Fabricated model, (a) Front view, (b) Ground plane view

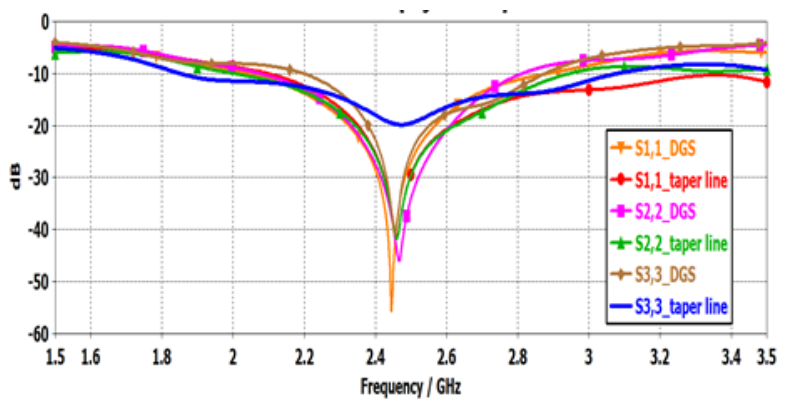

(a)

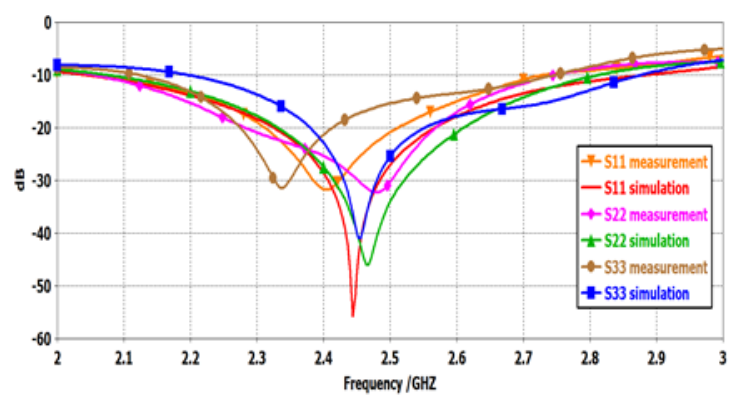

(b)

Figure 8. Return loss comparison, (a) Simulation of full and defected ground,

(b) Simulation and measurements of DGS model

Table 2. Return loss at $2.45 \mathrm{GHz}$ and bandwidth (BW) comparison

\begin{tabular}{ccccc}
\hline Beam port & Full ground return loss (dB) & DGS return loss (dB) & Full ground (BW) (MHz) & DGS (BW) (MHz) \\
\hline Port 1 & -47.72 & -38.31 & 1672 & 836 \\
Port 2 & -39.24 & -39.68 & 990 & 728 \\
Port 3 & -19.58 & -38.86 & 1220 & 672 \\
\hline
\end{tabular}

In addition, the radiation pattern simulation results after array elements connected to the lens for five beam ports at $2.45 \mathrm{GHz}$ are shown in Figure 9. A good agreement between simulation results using CST Microwave Studio and the measurements for radiation pattern is obtained. As a result of applying defected on the ground plane increasing in the beam scan angle $13^{\circ}, 26^{\circ}$ to $16^{\circ}$ and $29^{\circ}$ respectively for beam port one and port two can be realized because of the slow-wave propagation introduced by defected ground which adds an additional shift to the phase reached to the receive ports.

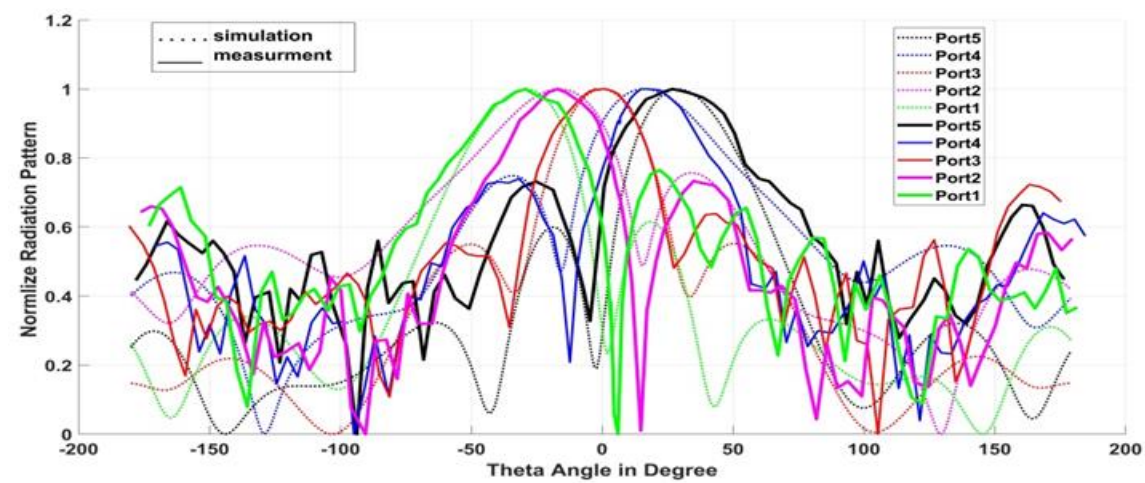

Figure 9. Radiation pattern for beam ports 


\section{CONCLUSION}

Microstrip Rotman lens has been designed and implemented to work with a center frequency of 2.45 $\mathrm{GHz}$. The tapering line matching technique was explained and implemented to provide matching between the lens and $50 \Omega$ ports. A new approach based on the defected ground structure was proposed in order to balance matching between ports and lens. As a result of the defected ground miniaturizing in the length of the designed lens was achieved with $23.67 \mathrm{~mm}$. Further, increasing the scan angle for beam ports was obtained by $3^{\circ}$ for beam port 2 and $3^{\circ}$ for beam port 1 . However, bandwidth is decreased as a result of applying defected on the ground plane for beam ports with average value $482 \mathrm{MHz}$ Furthermore; measurements are led to a good validation for the proposed simulation model.

\section{ACKNOWLEDGEMENTS}

The authors would like to acknowledge ORICC Universiti Tun Hussein Onn Malaysia (UTHM) for supporting this work.

\section{REFERENCES}

[1] G. Mumcu, M. Kacar and J. Mendoza, "Mm-Wave Beam Steering Antenna With Reduced Hardware Complexity Using Lens Antenna Subarrays," in IEEE Antennas and Wireless Propagation Letters, vol. 17, no. 9, pp. 1603-1607, Sept. 2018.

[2] M. Aldrigo, D. Masotti and M. Dragoman, "Smart two-dimensional material-based time modulated array for RFID applications," in IET Microwaves, Antennas \& Propagation, vol. 11, no. 15, pp. 2267-2272, 10122017.

[3] A. Singh, A. Kumar, A. Ranjan, A. Kumar, and A. Kumar, "Beam steering in antenna," in 2017 International Conference on Innovations in Information, Embedded and Communication Systems (ICIIECS), pp. 1-4, 2017.

[4] K. Pirapaharan, H. Kunsei, K. S. Senthilkumar, P. R.. Hoole, and S. R. H. Hoole, "A single beam smart antenna for wireless communication in a highly reflective and narrow environment," in 2016 International Symposium on Fundamentals of Electrical Engineering (ISFEE), pp. 1-5, 2016.

[5] S. Gao and Q. Luo, "Low-cost smart antennas for advanced wireless systems," in 2014 International Workshop on Antenna Technology: Small Antennas, Novel EM Structures and Materials, and Applications (iWAT), pp. 132-135, 2014.

[6] R. C. Hansen, "Phased Array Antennas," New York, USA: John Wiley \& Sons, Inc., 1998.

[7] W. Rotman and R. Turner, "Wide-angle microwave lens for line source applications," in IEEE Transactions on Antennas and Propagation, vol. 11, no. 6, pp. 623-632, November 1963.

[8] C. Metz et al., "Fully integrated automotive radar sensor with versatile resolution," in IEEE MTT-S International Microwave Sympsoium Digest (Cat. No.01CH37157), vol. 2, pp. 1115-1118, 2001.

[9] B. Holman, J. Graham, J. Skala, K. Bing, and M. A. Bruna, "Using a Rotman lens as a substitute for a multichannel antenna in a digitally beam-formed RADAR or SIGINT system," in 2015 IEEE Radar Conference (RadarCon), pp. 0490-0494, 2015.

[10] Z.-Y. Zhang, Y. Zhao, L. Ji, S.-L. Zuo, F. Xu, and G. Fu, "Design of multi-beam antenna based on Rotman lens," Int. J. RF Microw. Comput. Eng., vol. 28, no. 2, p. 1-10, Feb. 2018.

[11] R. C. Hansen, "Design trades for Rotman lenses," in IEEE Transactions on Antennas and Propagation, vol. 39, no. 4, pp. 464-472, April 1991.

[12] L. Schulwitz and A. Mortazawi, "A New Low Loss Rotman Lens Design Using a Graded Dielectric Substrate," in IEEE Transactions on Microwave Theory and Techniques, vol. 56, no. 12, pp. 2734-2741, Dec. 2008.

[13] Junwei Dong, A. I. Zaghloul, Rensheng Sun, and C. J. Reddy, "EHF Rotman lens for electronic scanning antennas," in 2008 Asia-Pacific Microwave Conference, pp. 1-4, 2008.

[14] Mohammed K. Al-Obaid, Ezri Mohd, Noorsaliza Abdullah, Samsul Haimi Dahlan, and Jawad Al," Design and implementation of microstrip Rotman lens for ISM band applications," Bulletin of Electrical Engineering and Informatics (BEEI), vol. 8, no. 1, pp. 83-89, March 2019.

[15] D. M. Pozar, "Microwave engineering," Wiley, 2012.

[16] C. A. Balanis, "Antenna theory : analysis and design," Wiley, 2016.

[17] M. S. Bhuiyan and N. C. Karmakar, "Defected Ground Structures for Microwave Applications," in Wiley Encyclopedia of Electrical and Electronics Engineering, Hoboken, NJ, USA: John Wiley \& Sons, Inc., pp. 1-31, 2014

[18] Chul-Soo Kim, Jun-Seok Park, Dal Ahn, and Jae-Bong Lim, "A novel 1-D periodic defected ground structure for planar circuits," in IEEE Microwave and Guided Wave Letters, vol. 10, no. 4, pp. 131-133, April 2000.

[19] Mukesh Kumar Khandelwal, Binod Kumar Kanaujia, and Sachin Kumar, "Defected Ground Structure: Fundamentals, Analysis, and Applications in Modern Wireless Trends," International Journal of Antennas and Propagation, vol. 2017, Article ID 2018527, pp. 1-22, 2017.

[20] Mussa Mabrok, Zahriladha Zakaria, Yully Erwanti Masrukin, Tole Sutikno, A.R. Othman and Nurhasniza Edward, "Switchable dual-band bandpass filter based on stepped impedance resonator with U-shaped defected microstrip structure for wireless applications," in Telecommunication, Computing, Electronics and Control (TELKOMNIKA), vol. 17, no. 2, pp. 1032-1039, Apr. 2019.

[21] Wai Loon Cheor, Azremi Abdullah Al-Hadi, Ping Jack Soh, and Mohd Faizal Jamlos, " Study of multiple antennas 
with defected ground slot for low-band LTE application," in Bulletin of Electrical Engineering and Informatics (BEEI), vol. 8, no. 1, pp. 83-89, March 2019.

[22] A. Belmajdoub, A. Boutejdar, A. El Alami, S. D. Bennani, and M. Jorio, "Design and optimization of a new compact 2.4 GHz-bandpass filter using DGS technique and U-shaped resonators for WLAN applications," in Telecommunication, Computing, Electronics and Control (TELKOMNIKA), vol. 17, no. 3, pp. 1081-1089, Jun. 2019.

[23] S. Elajoumi, A. Tajmouat, J. Zbitou, A. Errkik, A. M. Sanchez, and M. Jorio, "Bandwidth enhancement of compact microstrip rectangular antennas for UWB applications," in Telecommunication, Computing, Electronics and Control (TELKOMNIKA), vol. 17, no. 3, pp. 1559-1568, Jun. 2019.

[24] Ajay V.G, Parvathy A.R., and Thomaskutty Mathew, "Microstrip antenna with DGS based on CSRR array for WiMAX applications," in International Journal of Electrical and Computer Engineering (IJECE), vol. 9, no. 1, pp. 162-157, Feb. 2019.

[25] M. K. Mandal and S. Sanyal, "A novel defected ground structure for planar circuits," in IEEE Microwave and Wireless Components Letters, vol. 16, no. 2, pp. 93-95, Feb. 2006.

[26] Duk-Jae Woo, Taek-Kyung Lee, Jae-Wook Lee, Cheol-Sig Pyo and Won-Kyu Choi, "Novel U-slot and V-slot DGSs for bandstop filter with improved Q factor," in IEEE Transactions on Microwave Theory and Techniques, vol. 54, no. 6, pp. 2840-2847, June 2006.

\section{BIOGRAPHIES OF AUTHORS}

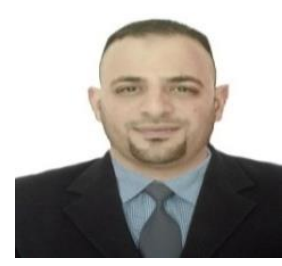

Mohammed Al-Obaid received a B.Sc. degree in Electronics and Communication Engineering from Baghdad University, Iraq in 2009, the M.S. degree in Electrical Engineering from Eastern Mediterranean University (EMU), N. Cyprus in 2014. He is currently working towards his $\mathrm{PhD}$ at the Faculty of Electrical and Electronic Engineering, Universiti Tun Hussein Onn Malaysia (UTHM), Malaysia. His research interests are an electronically steerable antenna, antenna design, and the phased array antenna.

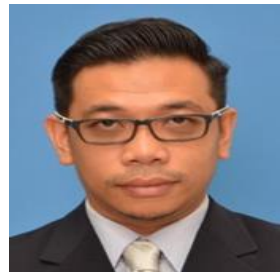

Ezri Mohd received his B.Eng. degrees in Electronics and Telecommunications from the Universiti Teknologi Malaysia (UTM), Malaysia, in 2003. He received his M.Eng in Electrical from Universiti Tun Hussein Onn Malaysia (UTHM). He worked as an Assistant Engineer at JK Wire Hardness from 2003-2004, then he joined Panasonic Audio Video as Engineer from 2004-2005. In 2005 he joined TDK Lamda as R\&D Engineer for two years. In 2007, he joined Universiti Tun Hussein Onn Malaysia (UTHM), Malaysia, as an Instructor Engineer. His research interest includes RF Filter Design, IoT applications, and Wireless Communication Systems.

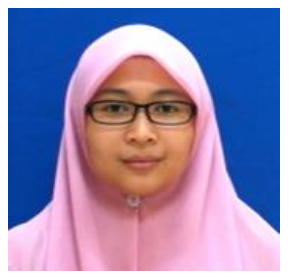

Noorsaliza Abdullah received B.Eng. and M.Eng. degrees in Electronics and Telecommunications from the Universiti Teknologi Malaysia (UTM), Malaysia, in 2003 and 2005, respectively, and her Ph.D. degree from Shizuoka University, Shizuoka, Japan, in 2012. In 2003, she joined Universiti Tun Hussein Onn Malaysia (UTHM), Malaysia, as a Tutor and awarded a scholarship to further her M.Eng. and Ph.D. degrees. Her research interest includes an array antenna, adaptive beamforming, and mobile communications.

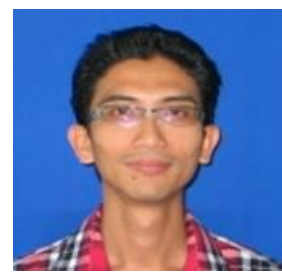

Samsul Haimi Dahlan received the Bachelor's degree in Engineering from the National University of Malaysia, Bangi, Malaysia, in 1999, the Master's degree in engineering from University Technology Malaysia, Bahru, Malaysia, in 2005, and the Ph.D. degree from University de Rennes 1, Rennes, France, in 2012. He is the Head of the Research Center for Applied Electromagnetics at Universiti Tun Hussein Onn Malaysia, Batu Pahat, Malaysia. His research interests include EMC, electromagnetic shielding, bioelectromagnetics, microwave devices, advanced antenna design, material characterization, and computational electromagnetics. 